\title{
METAL MATRIX COMPOSITE BRAKE ROTORS: HISTORICAL DEVELOPMENT AND PRODUCT LIFE CYCLE ANALYSIS
}

\author{
A.A. Adebisi ${ }^{1}$, M.A. Maleque ${ }^{1}$ and M.M. Rahman ${ }^{2}$ \\ ${ }^{1}$ Department of Manufacturing and Materials Engineering \\ International Islamic University Malaysia, Kuala Lumpur Malaysia \\ ${ }^{2}$ Faculty of Mechanical Engineering, Universiti Malaysia Pahang \\ 26600 Pekan, Kuantan, Pahang, Malaysia \\ E-mail: debisi1@yahoo.com
}

\begin{abstract}
Metal matrix composites (MMCs) have become attractive for engineering structural applications due to their excellent specific strength and are increasingly seen as an alternative to conventional materials, particularly in the automotive industry. In this study, a historical background on the development and application of metal matrix composites for automotive brake rotors is presented. The discussion also includes an analysis of the product life cycle with stir casting as a case study. The historical review analysis revealed that gradual development of material and processing techniques have led to lighter weight, lower cost and higher performance brake rotors as a result of a better understanding of the mechanics of metal matrix composites. It emerged from the study that the stir casting technique provides ease of operation, sustainability and, most significantly, very competitive costs without sacrificing quality relative to other techniques; as such, it is the most attractive manufacturing process in the industry. These findings can be used for future design and manufacture of an efficient and effective aluminium matrix composite brake rotor for automotive and other applications.
\end{abstract}

Keywords: Metal matrix composite; brake rotor; product life cycle; historical development.

\section{INTRODUCTION}

For the past 40 years, materials design has shifted emphasis on pursuing lightweight, environmentally friendly, low cost, high quality and better performance materials. Parallel to this trend, metal matrix composites (MMCs) have attracted growing interest for many applications (Kaczmar et al., 2000; Rohatgi et al., 1992; Chawla, 1992). MMC attributes include improved performance in terms of mechanical behaviour (e.g., tensile and compressive properties and tribology) and physical properties (e.g., density, thermal expansion and thermal diffusivity) by varying the weight fraction of the reinforcement phase. However, the low ductility and low-transverse creep resistance which developed due to hard particulate reinforcement are the major drawbacks that limit the usage of these materials in structural component applications. Substantial research effort has been directed towards developing an improved understanding of their potential and limitations invoking principles of physical metallurgy, stress analysis, processing sciences and applications.

In recent years, the development of MMCs has received worldwide attention on account of their superior strength and stiffness in addition to high wear resistance and 
creep resistance in comparison to their corresponding wrought alloys. Metal matrix composites have been used commercially in the automotive market for nearly 20 years. The properties of interest to the automotive industry include increased specific strength and stiffness, wear resistance, thermal conductivity and improved high-cycle fatigue resistance (Allison and Cole, 1993). Weight savings is also important in automotive applications with the need for achieving performance improvements with much lowercost materials and processes. There have been successful applications of MMCs in several automotive applications in which the combination of properties and cost satisfied a particular need. As a result of these successful applications, the Business Communications Company (BCC), Inc. (www.bccresearch.com) estimates that the global market for metal matrix composites consumed 4.1 million kilograms of materials in 2007 and 4.4 million kilograms in 2008. This is expected to increase to 5.9 million kilograms in 2013, with a compound annual growth rate (CAGR) of 5.9\%. The ground transportation segment has the largest share of the market and used 2.4 million kilograms of materials in 2008. This should reach 3.2 million kilograms in 2013, with a CAGR of $5.5 \%$ (Swift, 2009). Figure 1 shows the global metal matrix composite use by application and segment.

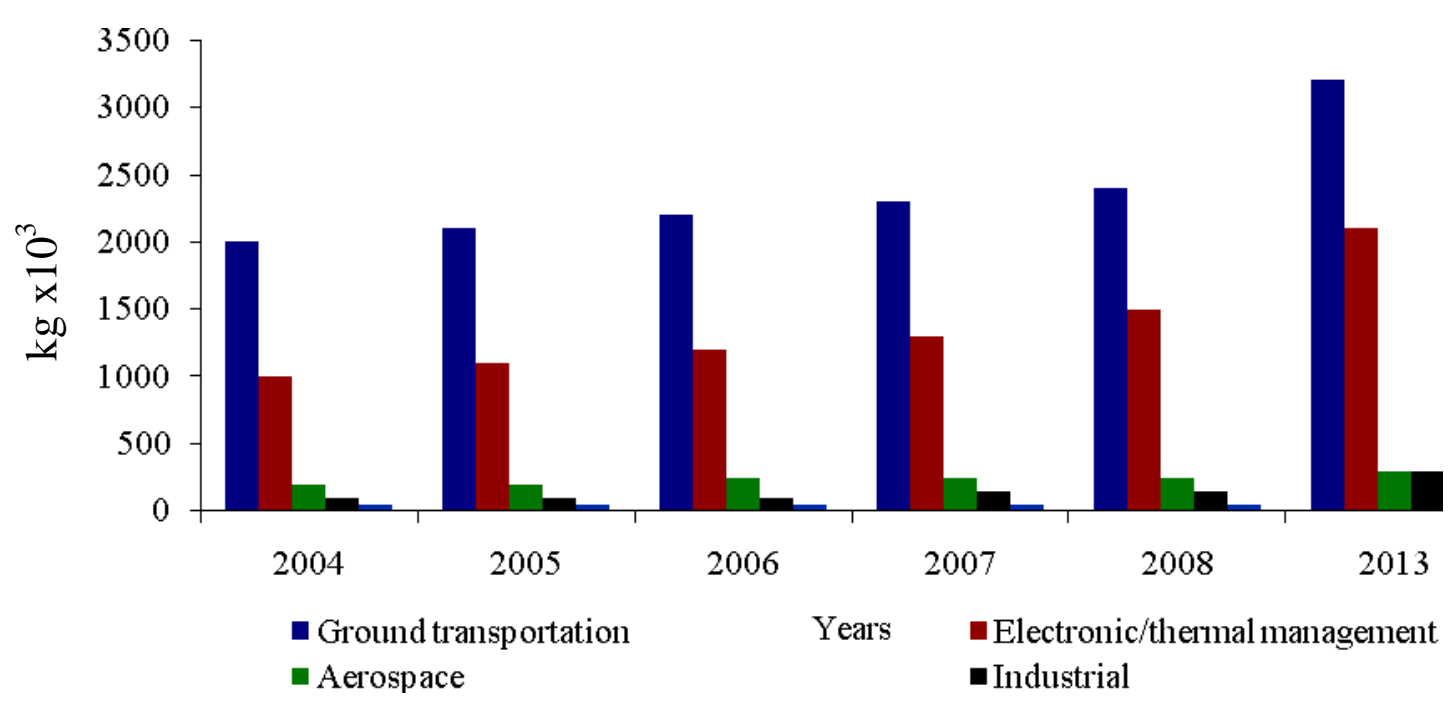

Figure 1. Global MMC outlook by application/segment, 2004 - 2013

[http://www.bccresearch.com/report/AVM012D.html]

In automotive applications, brake rotors have been held up as an example of where MMCs make a difference. In terms of weight, MMC rotor designs provide up to a $60 \%$ reduction when compared to cast iron. In addition, aluminium MMC rotors outperform their iron counterparts in terms of their mechanical properties and practical use. It has been found that the value of weight reduction in the automotive industry is between $\$ 0.35-\$ 3.50 / \mathrm{kg}$, depending on the vehicle platform. Therefore, a $7 \mathrm{~kg}$ iron rotor produced using an aluminium MMC at $50 \%$ of the weight could result in a savings of \$1.23-\$12.25. In the comparison of an aluminium MMC brake rotor vs. an iron brake rotor, the iron component will have higher value in terms of purchase price, postpurchase processing and maintainability, but the MMC component wins out in terms of performance and marketability (Bruski, 2000). 


\section{HISTORICAL REVIEW OF BRAKE ROTORS}

Brake rotor development and their use began in England in the 1890s. The first callipertype automobile brake rotor was patented by Frederick William Lanchester at Birmingham, UK in 1902 and was used successfully in Lanchester cars. However, the limited choice of metals in this period resulted in the use of copper as the braking medium acting on the rotor. A major advancement in brake technology came in 1918 with the invention of four-wheel hydraulic brake systems by Malcolm Loughead. The hydraulic brake system replaced the mechanical brake system that was in use at the time. The mechanical system had numerous disadvantages which made it difficult to brake all the wheels evenly, often causing a loss of control. Moreover, it required drivers to exert tremendous amounts of force on the brake pedal to slow the car. The hydraulic brake system multiplied the force that was applied to the brake, lessening the amount of force needed to be applied to the brake pedal by the driver. This system was first used in 1918 by Duesenberg; by 1929, four-wheel hydraulic braking systems were standard equipment on modern cars. Modern-style brake rotors first appeared on the low-volume Crosley Hotshot in 1949, although they had to be discontinued in 1950 due to design problems which significantly affected the life cycle of the brake rotor.

Aluminium matrix composites were first developed to meet very high performance needs for structural applications. Continuous fibre reinforced aluminium was used in the Space Shuttle and Hubble Space Telescope. Material cost became a more significant consideration and emphasis shifted toward particulate-reinforced materials, with the goal of a lower cost, higher volume product that could be used in automotive and commercial aerospace applications. Major aluminium companies had metal matrix composite development programmes in the 1980s and early 1990s. Alcan, through its Duralcan subsidiary, established a 36 million USD per year production capability for particulate-reinforced aluminium composites (Rittner, 2000). Automotive applications include cast aluminium composite brake drums and rotors on the Prowler and EV-1, driveshafts for the Corvette and GM S/T truck and tire studs in Scandinavia. In the aerospace field, aluminium composites are used in the fan exit guide vanes of the Pratt and Whitney 4000 series engines, which power the Boeing 777. Another exciting area of application for aluminium composites is in the fast-growing electronics packaging market, primarily for thermal management applications (as shown in Figure 1) in which the ability to match the coefficient of thermal expansion of the electronic materials is a key attribute.

Metal matrix composite brake rotors and drums are typically produced by casting processes such as semi-permanent gravity casting. Aluminium-magnesium and aluminium-silicon matrix alloys and both $\mathrm{SiC}$ and $\mathrm{Al}_{2} \mathrm{O}_{3}$ particle reinforcements have been used, typically of at least $20 \%$ by volume. A number of automobiles now use MMC brake components. The Lotus Elise used four discontinuously reinforced aluminium (DRA) brake rotors per vehicle from 1996 to 1998, and the specialty Plymouth Prowler has used DRA in the rear wheels since production started in 1997. Discontinuously reinforced aluminium rotors are particularly attractive in lightweight automobiles and are featured in the Volkswagen Lupo 3L and the Audi A2. In addition, a number of electric and hybrid vehicles, such as the Toyota RAV4, Ford Prodigy and the General Motors Precept, are reported to use MMC brake components (Miracle and Hunt, 2004). Figure 2 shows a selection of discontinuously reinforced aluminium (DRA) brake rotors. 


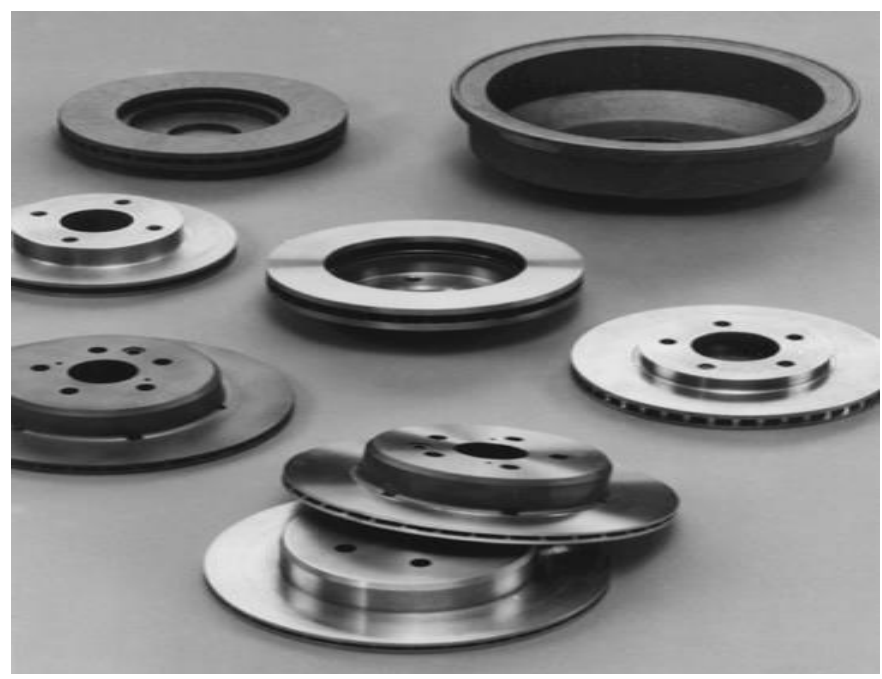

Figure 2. Discontinuously reinforced aluminium MMC brake rotors [http://www.mmc-assess.tuwien.ac.at]

\section{BRAKE ROTOR APPLICATIONS}

Aluminium-based MMCs offer a very useful combination of properties for brake system applications in the replacement of cast iron. Specifically, the wear resistance and high thermal conductivity of aluminium MMCs enable substitution in disk brake rotors, with an attendant weight savings on the order of 50 to $60 \%$. Because the weight reduction is unsprung, it also reduces inertial forces, providing an additional benefit in fuel economy. In addition, lightweight MMC rotors provide increased acceleration and reduced braking distance. It is reported that, based on brake dynamometer testing, MMC rotors reduce brake noise and wear, and have more uniform friction over the entire testing sequence compared to cast iron rotors (Miracle and Hunt, 2004). Table 1 shows the advantages of metal matrix composites over metals and other composites (Chawla and Chawla, 2006)

Table 1. Advantages of metal matrix composites (MMCs) over metals and other composites (polymer matrix composites PMCs)

\begin{tabular}{ll}
\hline \multicolumn{1}{c}{ Metals } & \multicolumn{1}{c}{ Other composites } \\
\hline $\begin{array}{l}\text { Major weight savings due to higher } \\
\text { strength-to-weight ratio }\end{array}$ & Higher strength and stiffness \\
$\begin{array}{l}\text { Exceptional dimensional stability (for } \\
\text { example, SiC/Al to Al) }\end{array}$ & $\begin{array}{l}\text { Higher thermal conductivity and service } \\
\text { temperatures }\end{array}$ \\
$\begin{array}{l}\text { Higher elevated temperature stability, } \\
\text { i.e., creep resistance }\end{array}$ & $\begin{array}{l}\text { Higher electrical conductivity (grounding, } \\
\text { space charging) }\end{array}$ \\
$\begin{array}{l}\text { Significantly improved cyclic fatigue } \\
\text { characteristics }\end{array}$ & $\begin{array}{l}\text { Better transverse properties and radiation } \\
\text { survivability (laser, UV, nuclear, etc.) }\end{array}$ \\
Better wear resistance & Improved joining characteristics \\
\hline
\end{tabular}

Aluminium is utilised as the most popular matrix for metal matrix composites (MMCs). Al alloys are quite attractive due to their low density, their ability to be strengthened by precipitation, their good corrosion resistance, high thermal and 
electrical conductivity and their high damping capacity. They are usually reinforced by SiC, $\mathrm{Al}_{2} \mathrm{O}_{3}$ and $\mathrm{C}$, but $\mathrm{TiB}_{2}, \mathrm{BeO}, \mathrm{BN}, \mathrm{B}_{4} \mathrm{C}, \mathrm{SiB}_{6}, \mathrm{Cr}_{3} \mathrm{C}_{2}, \mathrm{Gr}, \mathrm{TiB}, \mathrm{TiC}$ and $\mathrm{Si}$ may also be considered. In a previous study (Andreas, 2007), it was found that the usage of matrix and particle reinforcement materials varies by company. Figures 3 and 4 indicate that most companies use aluminium as the matrix material and $\mathrm{SiC}$ as the particle reinforcement.

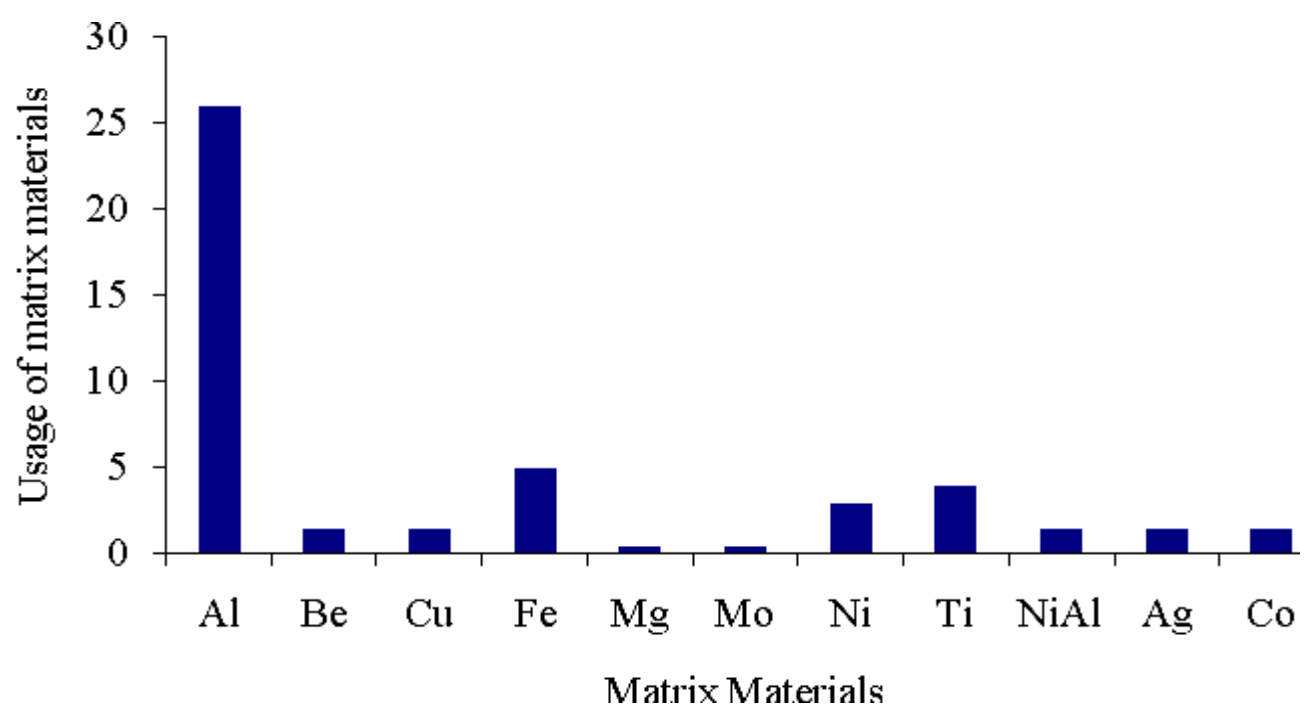

Figure 3. Usage of matrix materials

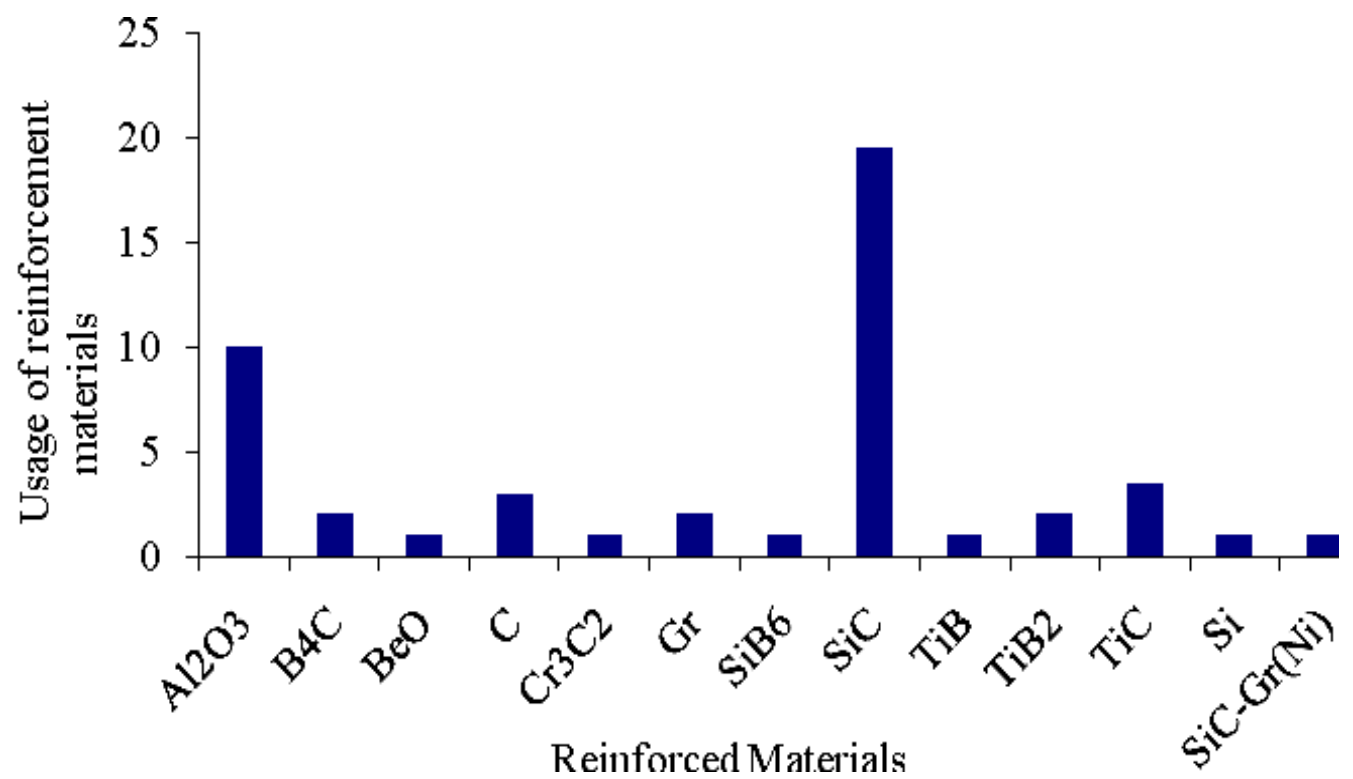

Figure 4. Usage of particulate reinforced materials

\section{PRODUCT LIFE CYCLE ANALYSIS}

The life cycle of a product is the length of time between its introduction on the market for the first time and the time when the production declines or stops working. The 
interval between the introduction and decline stage includes the growth and maturity stages of the product, which vary from a few months to several years, depending on its nature, usefulness, competition, environmental impact as well as technological development. The automotive industry has a relatively short life cycle as a result of rapid technological development, pressure due to competition and advanced research and development. Automobile parts (pistons, push rods, connecting rods, drive shafts and brake systems) have witnessed advancement in materials and manufacturing processes which in turn has influenced the life cycle analysis.

\section{Brake rotor life cycle}

The life cycle of an automotive brake rotor begins when it is introduced to the market after product development. This gives the opportunity for a new product as a result of material development and better processing technique. Initially, sales grow slowly at the introduction stage when the MMC brake rotor is new on the market due to the limited awareness of its performance and improved properties. Sales subsequently increase rapidly during the period of growth with the acceptance of an increasing number of customers as the market stabilises; at this point, the MMC brake rotor product becomes mature. As the brake rotor reaches maturity, it is overtaken by new developments with the introduction of superior competitors. In this period, it experiences a decline and may be eventually be withdrawn when new design modifications with new materials and manufacturing processes are developed to prolong the life cycle. From Figure 5, it can be seen that brake rotor life cycle consists of these four different stages: introduction, growth, maturity and decline.

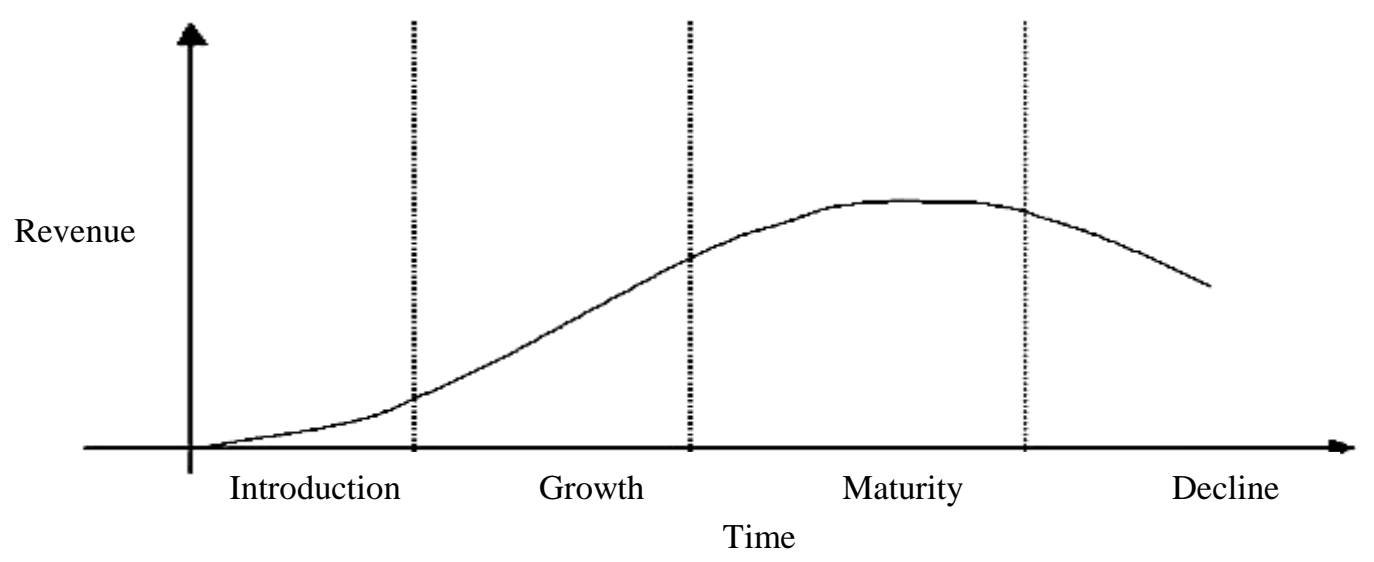

Figure 5. Automotive brake rotor life cycle

\section{Introduction Stage}

At the introduction (or development) stage, market share and growth are slow. Substantial research and development costs have been incurred in getting the MMC brake rotor to this stage. In addition, marketing costs may be high and it is unlikely that companies will make profits on newly developed products at this stage. The newly developed brake rotors are carefully monitored and advertised to ensure that they catch on. Otherwise, the best option may be to withdraw or cease production of the product. 
The need for immediate profit is not a pressure as the lack of it is expected at this time. The superior mechanical and thermal performance of the product is promoted to create awareness. If the MMC rotor has no or few competitors, a skimming price strategy is employed to maximise profits. Limited numbers of the product will be available through a few channels of distribution. Figure 6 shows the profit and loss for the product life cycle of a brake rotor; it clearly illustrates that heavy costs are incurred for research and development before the launch of the MMC brake rotor. This results in negative cash flow and great effort is usually applied to minimise this expenditure.

\section{Growth Stage}

The growth stage is characterised by rapid growth in sales and profits as the product becomes established. Profits rise due to an increase in output (economies of scale) and possibly better prices for raw materials and manufactured components. Competitors are few, sales grow and profit margins are good. At this stage, it is cheaper for the company to invest in increasing their market share as well as enjoying the overall growth of the market. Competitors are attracted into the market with very similar offerings. Advertising costs become high and focus upon developing the product brand, such as ventilated and solid brake rotors with various design concepts.

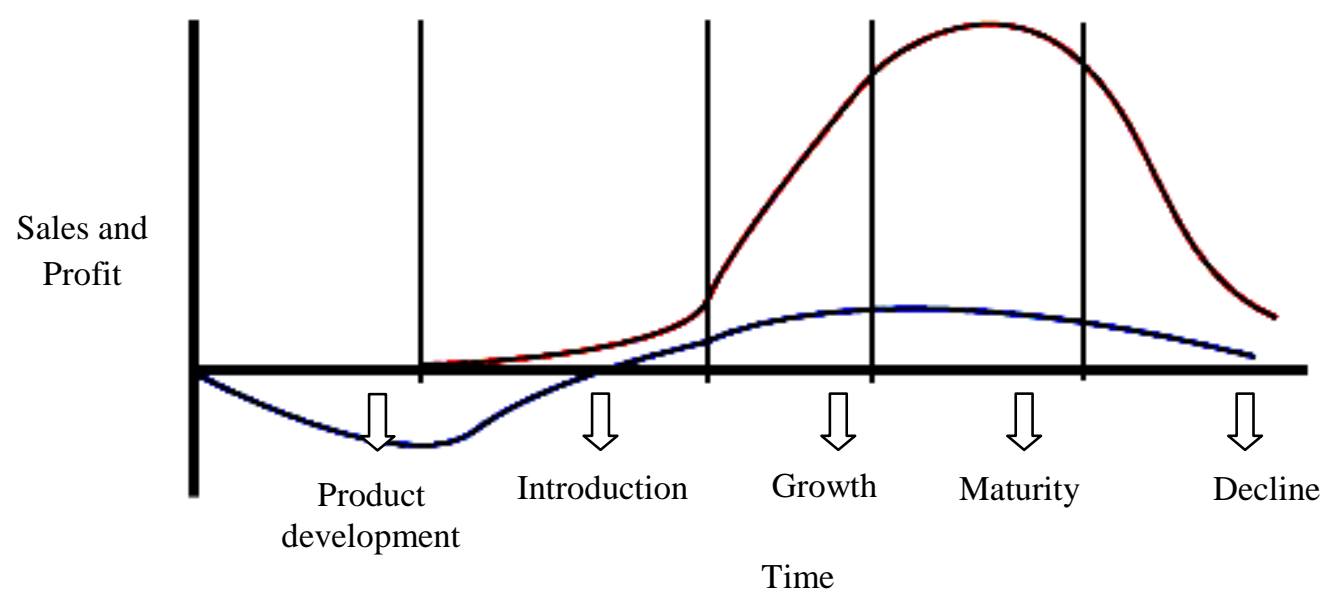

Figure 6. Profit and loss for the product life cycle of automotive brake rotor

\section{Maturity Stage}

It is in this stage where competition is most intense because the production rates are most efficient, the investment used in the MMC brake rotor development is recovered and most profits are made. In order to prolong the maturity stage, efforts should be made to develop new design modifications with new materials and manufacturing processes for the MMC brake rotor and also to adopt new marketing strategies. Introducing an improved version of the brake rotor can also prolong its life cycle. This will improve efficiency or extend the use of the product to new applications and environments. Improving fuel economy by reducing weight, reducing aerodynamic drag forces or improving the efficiency of the engine can extend the maturity stage. 


\section{Decline Stage}

At this stage, as a result of the appearance of other competitive advanced material brake rotors, processing techniques or technological advances, the MMC brake rotor may become less competitive, causing sales to decrease and the rotor to reach the decline stage. From the above study, it is not sufficient to design and manufacture a successful brake rotor. Researchers and engineers should continue to improve the effectiveness and efficiency of the brake rotor by making use of new technologies in order to improve the performance of the rotor.

\section{STIR CASTING OF ALUMINIUM METAL MATRIX COMPOSITE}

Stir casting is a unique and prominent technique for the development of reinforced aluminium matrix composite materials. This technique is utilised as a result of its simple process and ability to overcome the problem of expensive processing methods. This has restricted the widespread application of metal matrix composites, which are considered a potential material candidate for various structural and non-structural applications in the aerospace, automotive, biomedical, military defence and sports industries. The development of this promising technique evolved as a result of modern technological advancement in material applications and the demand for lightweight materials with improved mechanical and thermal properties. This process involves a liquid state fabrication technique which requires the incorporation of the reinforcing phase (discontinuous form) into the molten matrix metal (continuous form) to obtain a uniform distribution by stirring, as shown in Figure 7.

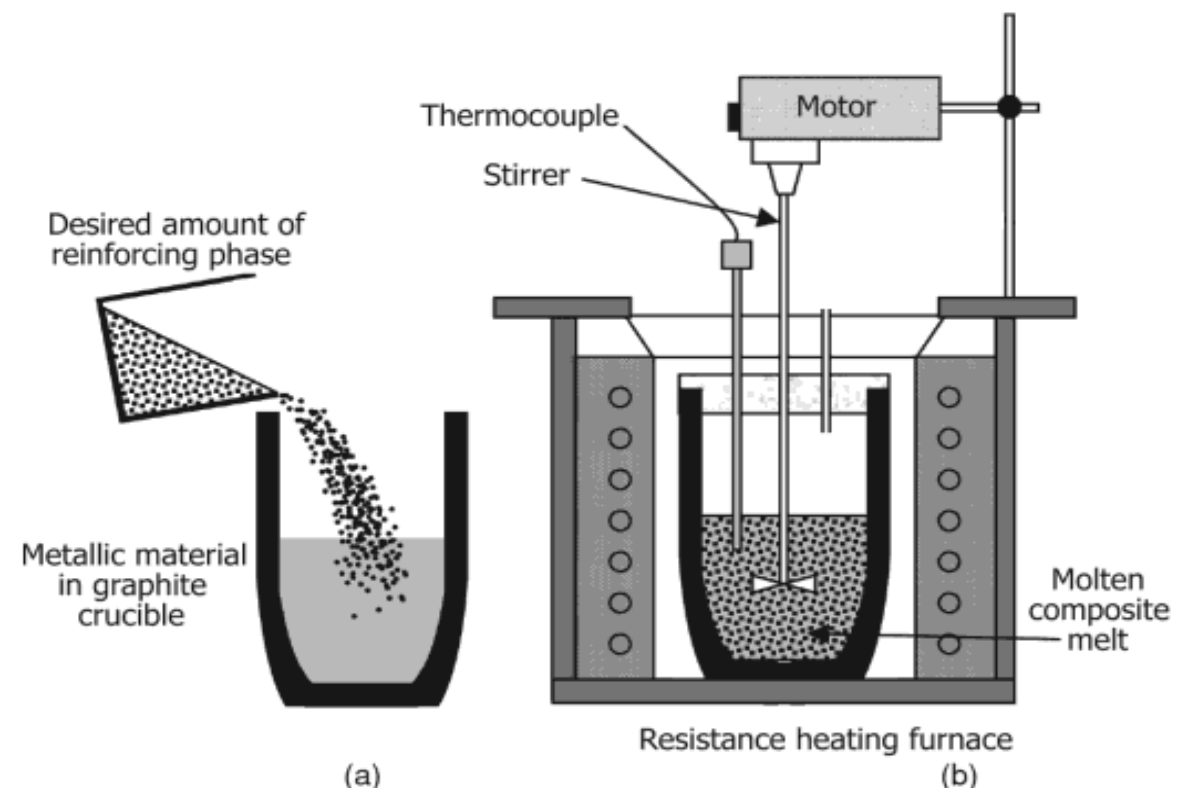

Figure 7. A schematic diagram showing (a) incorporation of the reinforcing phase into the matrix metallic material (b) the stir casting setup (Gupta and Sharon, 2011).

Ibrahim et al. (1991) and Lloyd (1994) reported that the vortex-mixing technique for the preparation of ceramic particle-dispersed aluminium matrix composites (AMC) was originally developed by Surappa and Rohatgi (1981) at the Indian Institute of 
Science. Subsequently, several aluminium companies further refined and modified the process, which is currently employed to manufacture a variety of AMCs on the commercial scale in various industries. The cost of production is about one-third (Skibo and Schuster, 1988) to one-half compared to other competitive methods such as centrifugal casting and powder metallurgy for large volume production. It is also anticipated that the cost of production will fall to one-tenth with further research and development. Figure 8 shows the material flow process for MMC brake rotor production using the stir casting process.

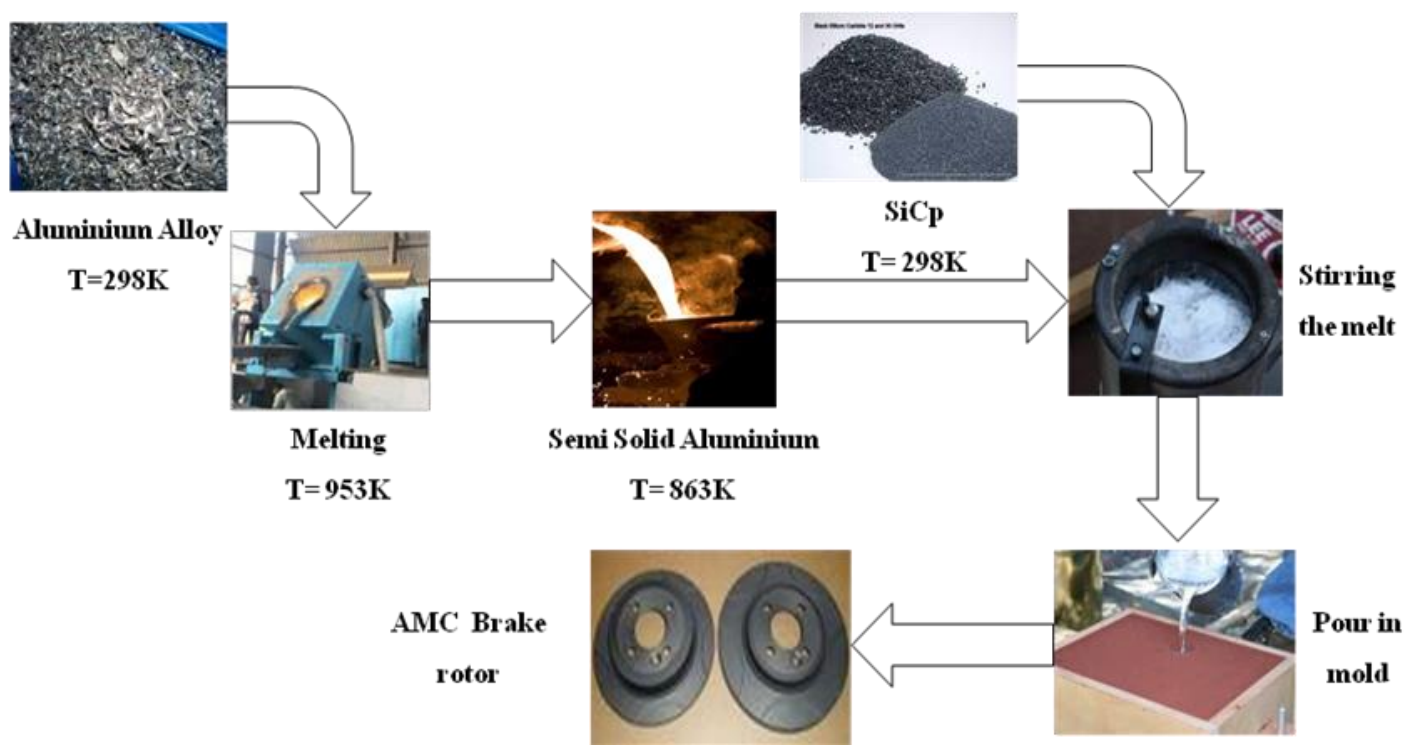

Figure 8. Material flow process for MMC brake rotor production

As seen in Figure 8, the aluminium alloy is heated to $953 \mathrm{~K}$ in a resistance-heated furnace. The molten metal is transferred to a graphite crucible in the semi-solid state and the silicon carbide particles are added. The mixture is then stirred to optimise uniform particle distribution into the melt. After stirring, the mixture is reheated and the developed composite is poured into a mould for solidification. The final product is the fabricated desired product, an AMC brake rotor.

\section{CONCLUSION}

The following conclusions can be drawn from the present study:

a. The historical review revealed that there was a gradual development of material and processing techniques for aluminium metal matrix composites.

b. The stir casting technique for aluminium matrix composite brake rotors is better than other techniques because it provides ease of operation, higher performance and better quality.

c. Developing new design modifications with advanced materials and manufacturing processes may prolong the life cycle of the MMC brake rotor.

d. Reviewing the present development provides the opportunity for further improvement of aluminium matrix composite brake rotors. 


\section{ACKNOWLEDGEMENTS}

The authors acknowledge the support of the department of Manufacturing and Materials Engineering, International Islamic University Malaysia and are also grateful to the Research Management Centre, International Islamic University Malaysia (IIUM), for financial support to conduct this research work under project EDW B 0906-332.

\section{REFERENCES}

Allison, J.E. and Cole, G.S. 1993. Metal-matrix composites in the automotive industry: opportunities and challenges. Journal of the Minerals, Metals and Materials Society, 45(1): 19-24.

Andreas, M. 2007. Metal matrix composite in industry: An overview, Switzerland. (http://mmc-assess.tuwien.ac.at/public/mmc_in_ind.pdf)

Bruski, R. 2000. Justify aluminium metal matrix composite in an era of cost reduction. Modern Casting, 90(2): 58-60.

Chawla, K.K. 1992. Composite materials science and engineering. New York: SpringerVerlag.

Chawla, N. and Chawla, K.K. 2006. Metal matrix composites. New York: Springer.

Gupta, M., and Sharon, N.M.L. 2011. Magnesium, magnesium alloys, and magnesium composites. New York: John Wiley \& Sons.

Ibrahim, I.A., Mohammed, F.A. and Lavernia, E.J. 1991. Particulate reinforced metal matrix composites - a review. Journal of Materials Science, 26(5): 1137-1156.

Kaczmar, J., Pietrzak, K. and Włosiński, W. 2000. The production and application of metal matrix composite materials. Journal of Materials Processing Technology, 106(1): 58-67.

Lloyd, D.J. 1990. High performance composites for the 1990s. S.K. Das (Warrendale, PA: TMS) USA. pp. 33-45.

Miracle, D.B. and Hunt, W.H. 2004. Automotive applications of metal matrix composites. Aluminium Consultant Group Inc., 1029-1032.

Rittner, M.N. 2000. Metal matrix composites in the $21^{\text {st }}$ century: markets and opportunities, Report GB-108R, Business Communications Company (BCC), Inc., Norwalk, CT.

Rohatgi, P.K., Ray, S. and Liu, Y. 1992. Tribological properties of metal matrixgraphite particle composites. International Materials Review, 37(3): 129-149.

Surappa, A.K. and Rohatgi, P.K. 1981. Preparation and properties of cast aluminiumceramic particle composites. Journal of Materials Science, 16(4): 983-993.

Skibo, M.D. and Schuster, D.M. 1988. Process for preparation of composite materials containing nonmetallic particles in a metallic matrix and composite materials made thereby. United States Patents, Patent No. 4,786,467.

Swift, C. 2009. Business Communications Company (BCC), Inch http://www.bccresearch.com/report/AVM012D.html, Report Code: AVM012D. 